\title{
Metformin therapy and postoperative atrial fibrillation in diabetic patients after cardiac surgery
}

\author{
Suresh Basnet ${ }^{1}$, Andrzej Kozikowski ${ }^{2^{*}}$ D, Haiyan Sun ${ }^{3}$, Melissa Troup ${ }^{4}$, Luis E. Urrutia, ${ }^{5,6}$ and Renee Pekmezaris ${ }^{2}$
}

\begin{abstract}
Background: Postoperative atrial fibrillation (AF) commonly occurs in cardiac surgery patients. Studies suggest inflammation and oxidative stress contribute to postoperative AF development in this patient population. Metformin exerts an anti-inflammatory effect that reduces oxidative stress and thus may play a role in preventing postoperative AF.

Methods: We conducted a matched, retrospective cohort study of diabetic patients' age $\geq 18$ undergoing a coronary artery bypass graft (CABG) and/or cardiac valve surgery from January 1, 2009, to November 30, 2014. We extracted data from The Society of Thoracic Surgeons National Adult Cardiac Surgery Database. Primary exposure was ongoing metformin use at a dose of $\geq 500 \mathrm{mg}$ in effect before cardiac surgery as captured before admission. Primary study outcome was postoperative AF incidence. Matching was used to reduce selection bias between metformin and non-metformin groups. Comparison between the groups after matching was accomplished using the McNemar test or paired $t$ test.

Results: Out of the 4177 patients with cardiac surgery (CABG and/or valve surgery), 1283 patients met our study criteria. These patients were grouped into metformin $[n=635(49.5 \%)]$ and non-metformin $[n=648(50.5 \%)]$ users. Pre-matching, postoperative AF was found in 149 (23.5\%) patients in the metformin group and 172 (26.5\%) in the non-metformin group ( $p=0.2088$ ). Matching resulted in a total of 114 patients in each group (metformin vs. non-metformin). We found no statistically significant difference for postoperative AF between the two groups after matching ( $p=0.8964)$.
\end{abstract}

Conclusions: Prior use of metformin therapy in diabetic patients undergoing cardiac surgery was not associated with decreased rate of postoperative AF.

Keywords: Cardiac surgery, Metformin, Postoperative atrial fibrillation, Diabetes

\section{Background}

The incidence trend of postoperative atrial fibrillation $(\mathrm{AF})$ has remained high over the last two decades, ranging from 10 to $65 \%$ depending on patient characteristics and preoperative as well as perioperative risk factors [1-4]. Postoperative AF is associated with greater resource utilization, prolonged hospital stays, increased morbidity, and in-hospital and long-term mortality [3-6].

The literature shows that beta blockers and antiarrhythmic agents decrease the risk of developing postoperative AF [7]. Thus, the American Association of

\footnotetext{
* Correspondence: akozikowski@nortwell.edu

${ }^{2}$ Department of Medicine, Northwell Health, Great Neck, NY, USA

Full list of author information is available at the end of the article
}

Thoracic Surgery and Canadian Cardiovascular Society both recommend the use of beta blockers and anti-arrhythmic agents such as amiodarone to prevent postoperative atrial fibrillation $[8,9]$. However, as of today, there is no standard therapy to effectively avoid the development of this wellknown postoperative cardiac surgery complication.

Metformin, an oral hypoglycemic agent, exerts an anti-inflammatory effect by reducing $\mathrm{C}$-reactive protein (CRP) in both humans [10] and animal models [11]. Esteghamati et al. showed that metformin significantly reduced YKL-40, a novel marker of inflammation and oxidative stress in patients newly diagnosed with type 2 diabetes (T2D) [12, 13]. Metformin therapy has also been found by Chang et al. to be associated with 
decreased risk of AF in patients with T2D not using other anti-diabetic agents [14].

With the exception of a few studies, the relationship between metformin use and the development of AF has not been investigated. The main objective of this study was to investigate the role of metformin therapy in the prevention of postoperative AF in diabetic cardiac surgical patients.

\section{Methods}

A retrospective cohort study was conducted utilizing data from The Society of Thoracic Surgeons (STS) Adult Cardiac Surgery Database Version 2.73. The STS National Database is one of the largest databases in medicine used in the analysis and reporting of risk-adjusted outcomes in cardiothoracic surgery [15]. The database contains over 5.9 million surgical records and collects data from approximately $90 \%$ of the US institutions that perform cardiac surgery [16]. A detailed description of the STS database design can be found elsewhere $[17,18]$. The database was utilized to obtain a list of eligible patients. Crossreferencing from the electronic medical record was conducted to obtain the remaining data elements needed for inclusion criteria (e.g., medications). Geisinger Institutional Review Board (IRB\#2014-0627) approval was obtained before study initiation.

Data extracted from the STS database included patient demographics (age, sex, race, body mass index (BMI), alcohol use), medical characteristics including hypertension, dyslipidemia, lung disease, peripheral artery disease, prior heart failure, prior myocardial infarction, chronic kidney disease (estimated glomerular filtration rate (eGFR) < $60 \mathrm{~mL} / \mathrm{min}$ ), glycated hemoglobin (HbA1C), and mitral valve disease/stenosis. We also collected preoperative and postoperative medication use including angiotensinconverting enzyme (ACE), angiotensin receptor blockers (ARB), acetylsalicylic acid (ASA), other anti-platelet, beta blocker lipid-lowering agents, steroids, vitamins $\mathrm{C}$ and $\mathrm{E}$, amiodarone, and magnesium sulfate. Lastly, we extracted cardiac characteristics data such as active myocardial infarction (STEMI), coronary artery bypass graft (CABG), valve surgery, cross-clamp time, explant position, intraaortic balloon pump, surgery status, and resuscitation.

\section{Exposure of interest}

The primary exposure of interest was continuous metformin use at a dose of $500 \mathrm{mg}$ or higher in effect before cardiac surgery as captured through the prior-to-admission medication listing using Clinical Decision Intelligence System (CDIS) at the study institution.

\section{Study sample}

All adult patients with diabetes age 18 years or older undergoing any major cardiac surgery at Geisinger
Health System from $1 / 1 / 2009$ to $11 / 30 / 2014$. Types of cardiac valve surgeries present were mitral and aortic, but no transcatheter aortic valve replacements. Patients were excluded if they had a history of AF or any other major cardiac arrhythmia before cardiac surgery.

\section{Sample size justification}

A power analysis was performed based on the assumption that the incidence of postoperative AF would be $22 \%$ for patients with metformin and 30\% for patients without metformin. In the Maisel et al. study, the incidence trend of postoperative AF ranged from 10 to $65 \%$ depending on patient characteristics [3]. In the Mathew et al. [4] and Mariscalco et al. [5] studies, the AF rate was $30 \%$ for patients without metformin. The study had $80.5 \%$ power to detect an absolute $8 \%$ difference between the metformin and non-metformin groups.

\section{Study end points}

The primary end point was the incidence of postoperative AF. The event of AF was assessed by the recording of a 12 lead electrocardiogram, from the continuous bedside monitor characterized by the absence of discrete $\mathrm{P}$ waves and an irregularly irregular ventricular rate. The occurrence of any new atrial fibrillation during the postoperative period, (i.e., immediately after the planned cardiac surgery until discharge from the hospital for that admission) was identified as post-operative atrial fibrillation. We also examined 30-day hospital readmission rate due to any arrhythmia and in-hospital postoperative acute renal failure (defined as a rise in serum creatinine of more than three-fold from baseline).

\section{Propensity score matching}

The propensity score matching method was used to reduce selection bias introduced by using a non-randomized design (Fig. 1.) [19]. The following variables, chosen from the STS database, were used to compute the propensity score for each patient: age, sex, race, BMI, alcohol consumption, hypertension, dyslipidemia, lung disease, peripheral artery disease, prior heart failure, prior myocardial infarction, chronic kidney disease (eGFR $<60 \mathrm{~mL} / \mathrm{min}$ ), $\mathrm{HbA} 1 \mathrm{C}$, mitral valve disease/stenosis, ACE or ARB use, ASA use, other anti-platelet use, beta blocker use, lipidlowering agent use, steroid use, vitamins $C$ and $E$ use, amiodarone use, magnesium sulfate use, active myocardial infarction, CABG, valve surgery, cross-clamp time, explant position, intra-aortic balloon pump, surgery status and resuscitation. The propensity score was estimated using logistic regression treating metformin use as the dependent variable. We then matched metformin users to non-users in a 1:1 ratio using the greedy method [20, 21]. Matching was evaluated using standardized differences [19-22]. If any standardized difference exceeded $10 \%$, then the 


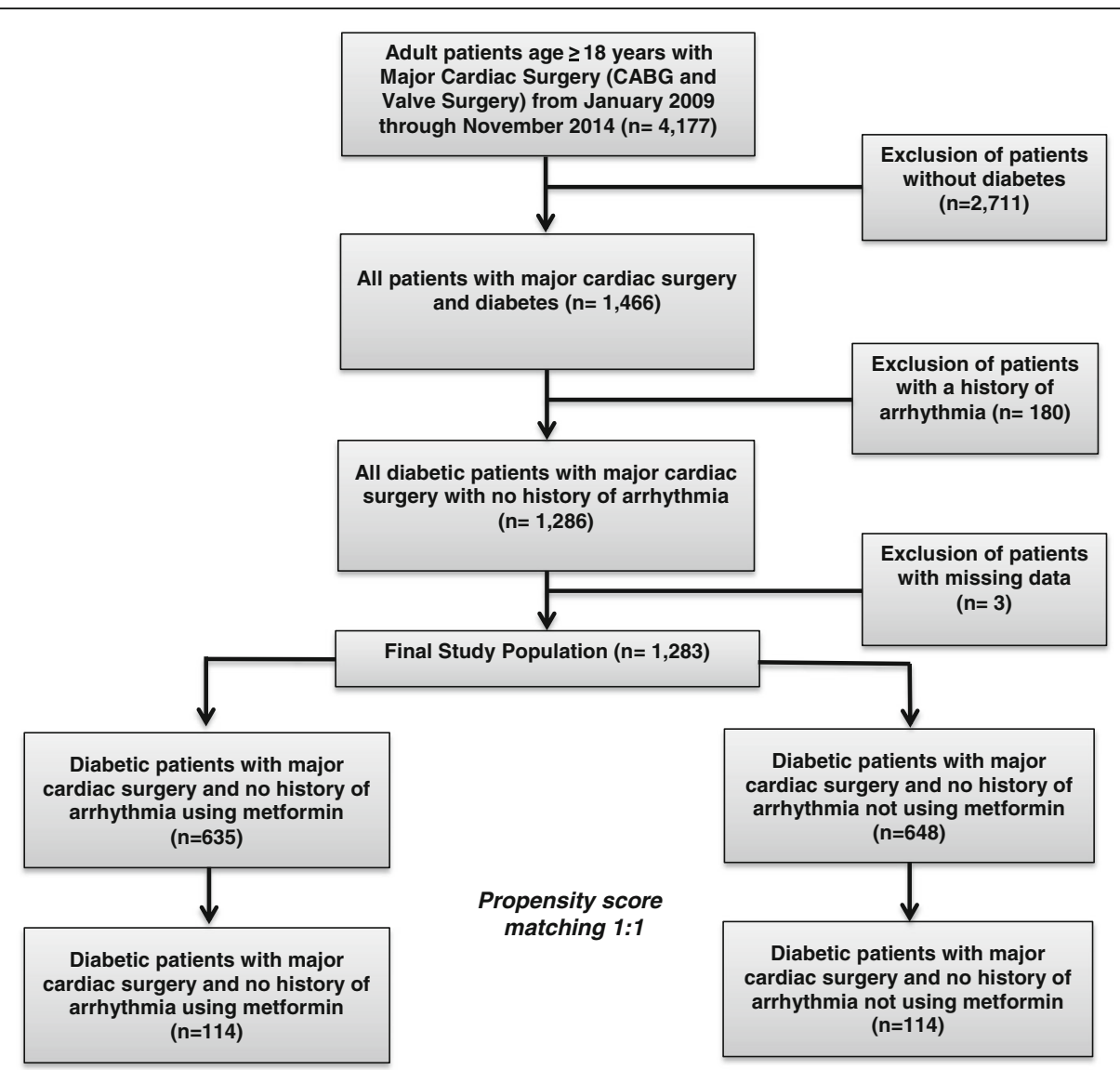

Fig. 1 Propensity score matching flow diagram. Major cardiac surgery = CABG (coronary artery bypass graft) and cardiac valve surgery

propensity model was re-evaluated and updated. The process was repeated until all standardized differences of the baseline variables were $<10 \%$.

\section{Statistical analysis}

Descriptive statistics were reported for the full sample and were stratified by the patients discharged with and without metformin therapy after cardiac surgery. Comparison between the groups before matching was accomplished using the chi-square or Fisher's exact tests, and twosample $t$ test or Wilcoxon rank sum test, as appropriate. Comparison between the groups after matching was accomplished using the McNemar test or paired $t$ test. We defined incident AF, arrhythmia, and acute renal failure as no AF, arrhythmia or acute renal failure being present 30 days before surgery (washout period $=30$ days). A $p$ value of less than 0.05 was considered statistically significant. Statistical analysis was performed using SAS version 9.4 (SAS Institute, Cary, NC).

\section{Results}

After excluding patients without diabetes, those with a history of arrhythmia and patients with missing data, the final sample size consisted of 1283 patients. There were 635 patients in the metformin prior-to-admission group and 648 in the non-metformin group. Demographic information, medical characteristics, preoperative medications use, postoperative medications use, and cardiac characteristics are summarized in Table 1, stratified by patients with or without metformin use before admission.

Patients in the metformin group, when compared to the non-metformin group, were more likely to be male (70.6 vs. $65.3 \% ; p=0.0431$ ) and younger (65.1 vs. 66.6; $p=0.0064)$, respectively. With regard to medical characteristics, patients in the metformin group, when compared to the non-metformin group had lower prior heart failure (7.6 vs. $13.6 \% ; p=0.0085)$ and MI rates (33.1 vs. 39.1\%: $p=0.0308$ ), lower CKD rates (38.3 vs. $57.3 \%$; $p<0.0001)$ and higher rates of $\mathrm{HbA} 1 \mathrm{C} \geq 9 \%$ (18.4 vs. $13.0 \% ; p=0.0197)$, respectively. Patients in the metformin group, when compared to the non-metformin group, were more likely to use ACE inhibitors or ARBs preoperatively within 48 h ( 47.0 vs. $38.9 \%$; $p=0.0197)$ and less likely to use other anti-platelets postoperatively (17.8 vs. $27.0 \% ; p=0.0001$ ), respectively. With regard to cardiac characteristics, patients in the metformin group 
Table 1 Comparability of the groups before matching

\begin{tabular}{|c|c|c|c|}
\hline Variable & Metformin prior to admission $(n=635)$ & Non-metformin prior to admission $(n=648)$ & $p$ value \\
\hline \multicolumn{4}{|l|}{ Demographics } \\
\hline Age, years, mean (SD) & $65.1(9.8)$ & $66.6(10.1)$ & 0.0064 \\
\hline Sex (male) & $448(70.6 \%)$ & $423(65.3 \%)$ & 0.0431 \\
\hline Race (white) & $628(98.9 \%)$ & $633(97.7 \%)$ & 0.0944 \\
\hline $\mathrm{BMI}, \mathrm{kg} / \mathrm{m}^{2}$, mean $(\mathrm{SD})$ & $32.37(6.0)$ & $32.13(6.9)$ & 0.4981 \\
\hline Alcohol use $\geq 2$ drinks per week & $\begin{array}{l}36(8.8 \%) \\
N=409\end{array}$ & $\begin{array}{l}27(6.8 \%) \\
N=397\end{array}$ & 0.2900 \\
\hline \multicolumn{4}{|l|}{ Medical characteristics } \\
\hline Hypertension & $571(89.9 \%)$ & $599(92.4 \%)$ & 0.1117 \\
\hline Dyslipidemia & $564(89.0 \%)$ & $572(88.3 \%)$ & 0.6985 \\
\hline Lung disease & $133(20.94 \%)$ & $154(23.8 \%)$ & 0.2255 \\
\hline Peripheral artery disease & $67(10.6 \%)$ & $78(12.1 \%)$ & 0.4007 \\
\hline Prior heart failure & $\begin{array}{l}28(7.6 \%) \\
N=368\end{array}$ & $\begin{array}{l}48(13.6 \%) \\
N=352\end{array}$ & 0.0085 \\
\hline Prior Ml & $\begin{array}{l}195(33.1 \%) \\
N=590\end{array}$ & $\begin{array}{l}234(39.1 \%) \\
N=599\end{array}$ & 0.0308 \\
\hline CKD (eGFR < $60 \mathrm{~mL} / \mathrm{min})$ & $243(38.3 \%)$ & $371(57.3 \%)$ & $<0.0001$ \\
\hline $\mathrm{HbA} 1 \mathrm{C} \geq 9 \%$ & $\begin{array}{l}104(18.4 \%) \\
N=566\end{array}$ & $\begin{array}{l}79(13.0 \%) \\
N=607\end{array}$ & 0.0115 \\
\hline Mitral valve disease/stenosis & $142(22.5 \%)$ & $169(26.4 \%)$ & 0.1127 \\
\hline \multicolumn{4}{|l|}{ Preoperative medications use } \\
\hline ACE or ARB (within 48 h) & $\begin{array}{l}193(47.0 \%) \\
N=411\end{array}$ & $\begin{array}{l}155(38.9 \%) \\
N=399\end{array}$ & 0.0197 \\
\hline ASA (within 5 days) & $555(87.4 \%)$ & $558(86.1 \%)$ & 0.4955 \\
\hline Other anti-platelets & $62(9.8 \%)$ & $58(9.0 \%)$ & 0.6170 \\
\hline Beta blocker (within 24 h) & $533(83.9 \%)$ & $561(86.6 \%)$ & 0.1827 \\
\hline Lipid lowering agents (within 24 h) & $572(90.1 \%)$ & $568(87.7 \%)$ & 0.1677 \\
\hline Steroids (within 24 h) & $19(3.0 \%)$ & $25(3.9 \%)$ & 0.3942 \\
\hline Vitamin C & $117(18.4 \%)$ & $108(16.7 \%)$ & 0.4076 \\
\hline Vitamin E & $19(3.0 \%)$ & $16(2.5 \%)$ & 0.5653 \\
\hline Amiodarone & $47(7.4 \%)$ & $52(8.0 \%)$ & 0.6758 \\
\hline Magnesium sulfate (inpatient) & $27(4.3 \%)$ & $21(3.2 \%)$ & 0.3399 \\
\hline \multicolumn{4}{|l|}{ Postoperative Medications Use } \\
\hline ACE or ARB & $254(41.1 \%)$ & $252(39.8 \%)$ & 0.6258 \\
\hline ASA & $593(96.0 \%)$ & $609(96.1 \%)$ & 0.9265 \\
\hline Other anti-platelets & $110(17.8 \%)$ & $171(27.0 \%)$ & 0.0001 \\
\hline Beta blocker & $583(94.3 \%)$ & $583(92.0 \%)$ & 0.0959 \\
\hline \multicolumn{4}{|l|}{ Cardiac characteristics } \\
\hline Active MI (STEMI) & $15(2.4 \%)$ & $16(2.5 \%)$ & 0.9008 \\
\hline CABG & $492(77.5 \%)$ & $506(78.1 \%)$ & 0.7940 \\
\hline Valve surgery & $227(35.8 \%)$ & $243(37.5 \%)$ & 0.5149 \\
\hline Cross clamp time $\geq 120$ & $\begin{array}{l}72(18.7 \%) \\
N=386\end{array}$ & $\begin{array}{l}101(24.4 \%) \\
N=414\end{array}$ & 0.0486 \\
\hline Explant position, aortic & $1(0.2 \%)$ & $2(0.3 \%)$ & 0.5751 \\
\hline Intra-aortic balloon pump & $77(12.1 \%)$ & $95(14.7 \%)$ & 0.1828 \\
\hline Surgery status & & & 0.2790 \\
\hline
\end{tabular}


Table 1 Comparability of the groups before matching (Continued)

\begin{tabular}{cll}
\hline Variable & Metformin prior to admission $(n=635)$ & Non-metformin prior to admission $(n=648)$ \\
\hline Emergent & $14(2.2 \%)$ & $20(3.1 \%)$ \\
Urgent & $257(40.5 \%)$ & $238(36.7 \%)$ \\
Elective & $364(57.3 \%)$ & $390(60.2 \%)$ \\
Resuscitation & $4(0.7 \%)$ & $7(1.2 \%)$ \\
& $N=590$ & $N=599$ \\
\hline
\end{tabular}

also had lower rates of cross-clamp time $\geq 120(18.7 \%$ vs. $24.4 ; p=0.0486)$. All variables presented in Table 1 were used to conduct propensity score matching. After matching, no significant differences were observed for any of the variables between the metformin and nonmetformin groups (see Table 2).

Table 3 presents comparisons between metformin and non-metformin groups for primary and secondary outcome variables before matching. Results for overall (CABG or valve surgery) showed that $23.5 \%$ of patients in the metformin group had developed new AF, $0.5 \%$ had acute renal failure, and $0.6 \%$ had 30 -day readmission with arrhythmia. In the non-metformin group, $26.5 \%$ patients developed new AF, $0.8 \%$ had acute renal failure, and $0.5 \%$ had 30-day readmission with arrhythmia. All comparisons between the metformin and non-metformin groups for the primary and secondary variables were not significant. Similarly, when comparing the two groups within CABG only and valve surgery only, there were no significant differences for new AF, acute renal failure, and 30-day readmission with arrhythmia.

After matching, $26.3 \%$ of patients in the metformin group had developed new AF, $0.9 \%$ had acute renal failure, and none had 30-day readmission with arrhythmia while $30.7 \%$ of patients in the non-metformin group developed new AF, none had acute renal failure, and $0.9 \%$ had 30-day readmission with arrhythmia (Table 4). There were no statistically significant differences between the two groups on the primary and secondary outcomes. Similarly, when analyzing CABG and valve surgery separately, there were no differences in all outcomes between patients in the metformin and non-metformin groups after matching.

\section{Discussion}

The main objective of our study was to investigate the role of metformin therapy in the prevention of postoperative AF in patients with diabetes who underwent cardiac surgery. The major findings of this propensity score matched study show that metformin use was not associated with a decreased risk of developing postoperative AF. The findings were similar even after separating the cardiac surgery into CABG or isolated valve surgery. Moreover, metformin use was also not associated with acute renal failure or 30-day readmission due to arrhythmia.

Several studies have suggested an important role of inflammation and oxidative stress as inciting factors in the development of postoperative AF in diabetic cardiac surgery patients [23-26]. A recent meta-analysis concluded that increased circulation inflammatory factors are associated with greater AF risk in the general population as well as for patients who underwent CABG [27]. Pre-operative use of statin drugs has shown promising results in preventing postoperative AF in multiple studies [28-30]. Some other novel therapies being tested for the prevention of this condition with conflicting beneficial effects are fish oil, vitamin C, vitamin E, polyunsaturated fatty acids, and corticosteroids [31-36]. Although metformin exerts an anti-inflammatory effect by reducing CRP levels $[11,12]$ in our study, it was not associated with lower postoperative AF risk in cardiac surgery patients.

Chang et al. [14] who performed a population-based study that included 645,710 patients with T2D found that metformin protected patients from developing new AF for at least 2 years during their 13-year follow-up period. However, this study did not include cardiac surgery patients. Moreover, in their study, the researchers only adjusted for 14 covariates, which did not include HbA1C, antioxidant use, and BMI. In our propensity score matched study, we controlled for 35 potentially confounding variables to better isolate the role of metformin in the development of postoperative AF in cardiac surgery patients.

One of the limitations of our study is that we did not have data on the exact use period of metformin. We abstracted metformin use data (a dose of $500 \mathrm{mg}$ or higher in effect before cardiac surgery) from the prior-to-admission medication listing using CDIS at the study institution. The absolute bioavailability of oral metformin ranges from 40 to $60 \%$, and absorption is complete within $6 \mathrm{~h}$ [37]; thus, patients receiving metformin in our study would be achieving steady-state plasma levels. However, it may be that the reduced inflammation requires a longer metformin use period. Previous research in clinical populations such as Cameron et al. found that metformin reduced inflammation with use period ranging from 4 to 6 months or longer [38]. In their retrospective cohort study, the use period of metformin was for at least 6 months, and in 
Table 2 Comparability of the groups after matching

\begin{tabular}{|c|c|c|c|}
\hline Variable & Metformin $(n=114)$ & Non-metformin $(n=114)$ & Standardized differences \\
\hline \multicolumn{4}{|l|}{ Demographics } \\
\hline Age, years (SD) & $66.0(9.2)$ & $66.0(9.7)$ & 0 \\
\hline Sex (male) & $83(72.8 \%)$ & $84(73.7 \%)$ & -0.02 \\
\hline Race (white) & $113(99.1 \%)$ & $114(100.0 \%)$ & -0.13 \\
\hline $\mathrm{BMI}, \mathrm{kg} / \mathrm{m}^{2}$ (SD) & $32.73(6.8)$ & $32.3(6.3)$ & 0.07 \\
\hline Alcohol use $\geq 2$ drinks per week & $7(6.1 \%)$ & $4(3.5 \%)$ & 0.12 \\
\hline \multicolumn{4}{|l|}{ Medical Characteristics } \\
\hline Hypertension & $105(92.1 \%)$ & $105(92.1 \%)$ & 0 \\
\hline Dyslipidemia & 107 (93.9\%) & $101(88.6 \%)$ & 0.19 \\
\hline Lung disease & $29(25.4 \%)$ & $32(28.1 \%)$ & -0.06 \\
\hline Peripheral artery disease & $11(9.7 \%)$ & $11(9.7 \%)$ & 0 \\
\hline Prior heart failure & $12(10.5 \%)$ & $10(8.8 \%)$ & 0.06 \\
\hline Prior Ml & $40(35.1 \%)$ & $35(30.7 \%)$ & 0.09 \\
\hline CKD (eGFR < 60 mL/min) & $49(43.0 \%)$ & $52(45.6 \%)$ & -0.05 \\
\hline $\mathrm{HbA} 1 \mathrm{C} \geq 9 \%$ & $16(14.0 \%)$ & 17 (14.9\%) & -0.02 \\
\hline Mitral valve disease/stenosis & $55(48.3 \%)$ & $51(44.7 \%)$ & 0.07 \\
\hline \multicolumn{4}{|l|}{ Preoperative medications use } \\
\hline ACE or ARB (within 48 h) & $55(48.3 \%)$ & $54(47.4 \%)$ & 0.02 \\
\hline ASA (within 5 days) & $98(89.0 \%)$ & $101(88.6 \%)$ & 0.01 \\
\hline Other anti-platelets & $5(4.4 \%)$ & $9(7.9 \%)$ & -0.14 \\
\hline Lipid lowering agents (within 24 h) & $103(90.4 \%)$ & $101(88.6 \%)$ & \\
\hline Steroids (within 24 h) & $1(0.9 \%)$ & $2(1.8 \%)$ & 0.06 \\
\hline Vitamin C & $21(18.4 \%)$ & $21(18.4 \%)$ & 0 \\
\hline Vitamin $\mathrm{E}$ & $2(1.8 \%)$ & $1(0.9 \%)$ & 0.08 \\
\hline Amiodarone & $5(4.4 \%)$ & $7(6.1 \%)$ & -0.07 \\
\hline Magnesium sulfate (inpatient) & $3(2.6 \%)$ & $3(2.6 \%)$ & 0 \\
\hline \multicolumn{4}{|l|}{ Postoperative medications use } \\
\hline ACE or ARB & $60(52.6 \%)$ & $52(45.6 \%)$ & 0.14 \\
\hline ASA & $110(96.5 \%)$ & $110(96.5 \%)$ & 0 \\
\hline Other anti-platelets & $23(20.2 \%)$ & $23(20.2 \%)$ & 0 \\
\hline Beta blocker & $104(91.2 \%)$ & $106(93.0 \%)$ & -0.07 \\
\hline \multicolumn{4}{|l|}{ Cardiac characteristics } \\
\hline Active MI (STEMI) & $1(0.9 \%)$ & $1(0.9 \%)$ & 0 \\
\hline CABG & $82(71.9 \%)$ & $82(71.9 \%)$ & 0 \\
\hline Valve surgery & $53(46.5 \%)$ & $54(47.4 \%)$ & -0.02 \\
\hline Cross clamp time $\geq 120$ & $19(16.7 \%)$ & $13(11.4 \%)$ & 0.15 \\
\hline Explant position, aortic & $1(0.9 \%)$ & $1(0.9 \%)$ & 0 \\
\hline Intra-aortic balloon pump & $12(10.5 \%)$ & $12(10.5 \%)$ & 0 \\
\hline \multicolumn{4}{|l|}{ Surgery status } \\
\hline Emergent & $2(1.8 \%)$ & $2(1.8 \%)$ & 0 \\
\hline Urgent & 35 (30.7\%) & $32(28.1 \%)$ & 0.06 \\
\hline Elective & 77 (67.5\%) & $80(70.2 \%)$ & -0.06 \\
\hline Resuscitation & $1(0.9 \%)$ & $1(0.9 \%)$ & 0 \\
\hline
\end{tabular}


Table 3 Analyses of primary and secondary outcome variables before propensity score matching

\begin{tabular}{|c|c|c|c|}
\hline Variable & Metformin $(n=635) 49.5 \%$ & Non-metformin $(n=648) 50.4 \%$ & $p$ value \\
\hline \multicolumn{4}{|l|}{ Overall (CABG or valve surgery) } \\
\hline New atrial fibrillation & $149(23.5 \%)$ & $172(26.5 \%)$ & 0.2088 \\
\hline $\begin{array}{l}\text { Acute renal failure } \\
\text { This is defined as } 3 \text {-fold increase in creatinine from baseline on admission) }\end{array}$ & $3(0.5 \%)$ & $5(0.8 \%)$ & 0.7258 \\
\hline 30-day readmission with arrhythmia & $4(0.6 \%)$ & $3(0.5 \%)$ & 0.7232 \\
\hline CABG only & $N=408$ & $N=405$ & \\
\hline New atrial fibrillation & $81(19.9 \%)$ & $91(22.5 \%)$ & 0.3707 \\
\hline Acute renal failure & $0(0.0 \%)$ & $2(0.5 \%)$ & 0.2479 \\
\hline 30-day readmission with arrhythmia & $2(0.5 \%)$ & $2(0.5 \%)$ & 0.9999 \\
\hline Valve surgery only & $N=143$ & $N=142$ & \\
\hline New atrial fibrillation & $38(26.6 \%)$ & $39(27.5 \%)$ & 0.8655 \\
\hline Acute renal failure & $2(1.4 \%)$ & $0(0.0 \%)$ & 0.4982 \\
\hline 30-day readmission with arrhythmia & $1(0.7 \%)$ & $0(0.0 \%)$ & 0.9999 \\
\hline
\end{tabular}

their randomized placebo-controlled study patients in the metformin arm received the medication for 4 months. Propensity score matching decreases selection bias by balancing measured covariates; the larger the number of covariates used to construct the propensity score, the better the balance between the groups. In our study, we used 35 variables to construct the propensity score which included many of the variables shown in the literature to have an effect on postoperative AF. Unfortunately, we did not have data regarding diabetes duration and could not adjust for this variable. Moreover, only randomization can balance the unmeasured confounders; thus, hidden bias may remain in the present study.

Another limitation in our study is that the vast majority of patients were white. The relationship between metformin use and postoperative AF may be different for other races/ethnicities. For example, African American individuals may have a significantly improved glycemic response to metformin when compared with white Americans [39]. Moreover, the Diabetes Prevention Program study, comparing Asian with white patients, showed greater risk reduction for T2D incidence from metformin use (38 vs. 24\%) [40].

\section{Conclusions}

In our study, prior use of metformin therapy was not associated with the incidence of postoperative AF in diabetic patients undergoing cardiac surgery. With only a few studies exploring the relationship between metformin use and postoperative AF conducted to date, future randomized controlled trials are needed with more diverse patient populations.

Table 4 Analyses of primary and secondary outcome variables after propensity score matching

\begin{tabular}{|c|c|c|c|}
\hline Variable & Metformin $(n=114) \%$ & Non-metformin $(n=114) \%$ & $p$ value \\
\hline \multicolumn{4}{|l|}{ Overall (CABG or valve surgery) } \\
\hline New atrial fibrillation & $30(26.3 \%)$ & $35(30.7 \%)$ & 0.4658 \\
\hline Acute renal failure & $1(0.9 \%)$ & $0(0.0 \%)$ & NA \\
\hline 30-day readmission with arrhythmia & $0(0.0 \%)$ & $1(0.9 \%)$ & NA \\
\hline CABG only & $N=85$ & $N=85$ & \\
\hline New atrial fibrillation & $18(21.2 \%)$ & $24(28.4 \%)$ & 0.2733 \\
\hline Acute renal failure & $1(1.2 \%)$ & $0(0.0 \%)$ & NA \\
\hline 30-day readmission with arrhythmia & $0(0.0 \%)$ & $1(1.2 \%)$ & NA \\
\hline Valve surgery only & $N=57$ & $N=57$ & \\
\hline New atrial fibrillation & 19 (33.3\%) & $22(38.6 \%)$ & 0.5775 \\
\hline Acute renal failure & $0(0.0 \%)$ & $0(0.0 \%)$ & NA \\
\hline 30-day readmission with arrhythmia & $0(0.0 \%)$ & $0(0.0 \%)$ & NA \\
\hline
\end{tabular}




\section{Abbreviations}

ACE: Angiotensin-converting enzyme; AF: Atrial fibrillation; ARB: Angiotensin receptor blockers; BMI: Body mass index; CABG: Coronary artery bypass graft; CDIS: Clinical decision intelligence system; CRP: C-reactive protein; IL-6: Interleukin-6; IQR: Interquartile range; STEMI: ST-segment elevation myocardial infarction; STS: Society of Thoracic Surgeons; T2D: Type 2 diabetes

\section{Acknowledgements}

None.

\section{Funding}

None.

\section{Availability of data and materials}

The datasets generated during and/or analyzed during the current study are available from the corresponding author.

\section{Authors' contributions}

All the authors equally contributed to the conception, data collection, statistical analysis, and drafting of the manuscript. All the authors approved the final submitted version of the manuscript.

\section{Ethics approval and consent to participate}

The study was approved by the Geisinger Institutional Review Board (IRB\#2014-0627) before study initiation.

\section{Consent for publication}

Not applicable.

\section{Competing interests}

The authors declare that they have no competing interests.

\section{Publisher's Note}

Springer Nature remains neutral with regard to jurisdictional claims in published maps and institutional affiliations.

\section{Author details}

'Department of Critical Care Medicine, Valley Health System, Winchester, VA, USA. ${ }^{2}$ Department of Medicine, Northwell Health, Great Neck, NY, USA. ${ }^{3}$ Biostatistics Core, Geisinger Medical Center, Danville, PA, USA.

${ }^{4}$ Investigator-Initiated Research Operations, Geisinger Medical Center, Danville, PA, USA. ${ }^{5}$ Department of Critical Care Medicine, Geisinger Medical Cent, Danville, PA, USA. ${ }^{6}$ Department of Cardiovascular Medicine, Geisinger Medical Center, Danville, PA, USA.

Received: 19 July 2017 Accepted: 10 October 2017

Published online: 18 October 2017

\section{References}

1. Maisel WH, Rawn JD, Stevenson WG. Atrial fibrillation after cardiac surgery. Ann Intern Med. 2001:135:1061-73.

2. Mathew JP, Fontes ML, Tudor IC, Ramsay J, Duke P, Mazer CD, et al. A multicenter risk index for atrial fibrillation after cardiac surgery. J Am Med Assoc. 2004;291:1720-9.

3. Villareal RP, Hariharan R, Liu BC, Kar B, Lee V-V, Elayda M, et al. Postoperative atrial fibrillation and mortality after coronary artery bypass surgery. J Am Coll Cardiol. 2004:43:742-8.

4. Mariscalco G, Klersy C, Zanobini M, Banach M, Ferrarese S, Borsani P, et al. Atrial fibrillation after isolated coronary surgery affects late survival. Circulation. 2008:118:1612-8

5. Bramer S, van Straten AHM, Soliman Hamad MA, Berreklouw E, Martens EJ, Maessen JG. The impact of new-onset postoperative atrial fibrillation on mortality after coronary artery bypass grafting. Ann Thorac Surg. 2010:90:443-9.

6. Saxena A, Dinh DT, Smith JA, Shardey GC, Reid CM, Newcomb AE. Usefulness of postoperative atrial fibrillation as an independent predictor for worse early and late outcomes after isolated coronary artery bypass grafting: multicenter Australian study of 19,497 patients. Am J Cardiol. 2012;109:219-25.
7. Arsenault KA, Yusuf AM, Crystal E, Healey JS, Morillo CA, Nair GM, et al. Interventions for preventing post-operative atrial fibrillation in patients undergoing heart surgery. Cochrane Database Syst Rev. 2013;1:CD003611.

8. Mitchell LB. Canadian Cardiovascular Society atrial fibrillation guidelines 2010: prevention and treatment of atrial fibrillation following cardiac surgery. Can J Cardiol. 2011;27:91-7.

9. Frendl G, Sodickson AC, Chung MK, Waldo AL, Gersh BJ, Tisdale JE, et al. AATS guidelines for the prevention and management of perioperative atrial fibrillation and flutter for thoracic surgical procedures. J Thorac Cardiovasc Surg 2014;148. 2014:e153-93.

10. Morin-Papunen L, Rautio K, Ruokonen A, Hedberg P, Puukka M, Tapanainen JS. Metformin reduces serum $C$-reactive protein levels in women with polycystic ovary syndrome. J Clin Endocrinol Metab. 2003:88:4649-54.

11. Salman ZK, Refaat R, Selima E, Sarha A El, Ismail MA. The combined effect of metformin and I-cysteine on inflammation, oxidative stress and insulin resistance in streptozotocin-induced type 2 diabetes in rats. Eur J Pharmacol 2013:714:448-455

12. Esteghamati A, Rezvani S, Khajeh E, Ebadi M, Nakhjavani M, Noshad S. Comparative effects of metformin and pioglitazone on YKL-40 in type 2 diabetes: a randomized clinical trial. J Endocrinol Investig. 2014;37:1211-8.

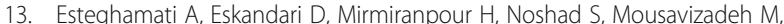
Hedayati $M$, et al. Effects of metformin on markers of oxidative stress and antioxidant reserve in patients with newly diagnosed type 2 diabetes: a randomized clinical trial. Clin Nutr. 2013:32:179-85.

14. Chang S-H, Wu L-S, Chiou M-J, Liu J-R, Yu K-H, Kuo C-F, et al. Association of metformin with lower atrial fibrillation risk among patients with type 2 diabetes mellitus: a population-based dynamic cohort and in vitro studies. Cardiovasc Diabetol. 2014:13:1-8

15. Ferguson TB Jr, Dziuban SW Jr, Edwards FH, Eiken MC, Shroyer ALW Pairolero PC, et al. The STS National Database: current changes and challenges for the new millennium. Ann Thorac Surg. 2000;69:680-91.

16. The Society of Thoracic Surgeons Fact Sheet. 2017 . Available from: http:// www.sts.org/media/sts-fact-sheet. [cited 2017 May 1]

17. Jacobs JP, Shahian DM, He X, O'Brien SM, Badhwar V Cleveland JC Jr, et al. Penetration, completeness, and representativeness of the society of thoracic surgeons adult cardiac surgery database. Ann Thorac Surg. 2016;101:33-41.

18. Grover FL, Shahian DM, Clark RE, Edwards FH. The STS National Database. Ann Thorac Surg. 2014;97:S48-54.

19. Rosenbaum $P R$, Rubin DB. Reducing bias in observational studies using subclassification on the propensity score. J Am Stat Assoc. 1984;79:516-24.

20. Rosenbaum PR. Design of observational studies. New York, NY: Springer New York; 2010

21. Austin PC. An introduction to propensity score methods for reducing the effects of confounding in observational studies. Multivariate Behav Res. 2011;46:399-424.

22. Normand S-LT, Landrum MB, Guadagnoli E, Ayanian JZ, Ryan TJ, Cleary PD, et al. Validating recommendations for coronary angiography following acute myocardial infarction in the elderly: a matched analysis using propensity scores. J Clin Epidemiol. 2001;54:387-98.

23. Aviles RJ, Martin DO, Apperson-Hansen C, Houghtaling PL, Rautaharju P, Kronmal RA, et al. Inflammation as a risk factor for atrial fibrillation. Circulation. 2003:108:3006-10.

24. Gaudino M, Andreotti F, Zamparelli R, Di Castelnuovo A, Nasso G, Burzotta F, et al. The $-174 \mathrm{G} / \mathrm{C}$ interleukin-6 polymorphism influences postoperative interleukin-6 levels and postoperative atrial fibrillation. Is atrial fibrillation an inflammatory complication? Circulation. 2003;108:II-195-9.

25. Chung MK, Martin DO, Sprecher D, Wazni O, Kanderian A, Carnes CA, et al. C-reactive protein elevation in patients with atrial arrhythmias inflammatory mechanisms and persistence of atrial fibrillation. Circulation. 2001;104:2886-91.

26. Li J, Solus J, Chen Q, Rho YH, Milne G, Stein CM, et al. Role of inflammation and oxidative stress in atrial fibrillation. Hear Rhythm. 2010;7:438-44.

27. Wu N, Xu B, Xiang $Y$, Wu L, Zhang $Y, M a X$, et al. Association of inflammatory factors with occurrence and recurrence of atrial fibrillation: a meta-analysis. Int J Cardiol. 2013;169:62-72.

28. Liakopoulos OJ, Kuhn EW, Slottosch I, Wassmer G, Wahlers T. Preoperative statin therapy for patients undergoing cardiac surgery. Cochrane Database Syst Rev. 2012;4:CD008493.

29. Fauchier L, Pierre B, de Labriolle A, Grimard C, Zannad N, Babuty D. Antiarrhythmic effect of statin therapy and atrial fibrillation: a meta-analysis of randomized controlled trials. J Am Coll Cardiol. 2008;51:828-35. 
30. Chopra V. Effect of perioperative statins on death, myocardial infarction, atrial fibrillation, and length of stay: a systematic review and meta-analysis. Arch Surg. 2012;147:181.

31. Mozaffarian D, Wu JHY, de Oliveira Otto MC, Sandesara CM, Metcalf RG, Latini $R$, et al. Fish oil and post-operative atrial fibrillation: a meta-analysis of randomized controlled trials. J Am Coll Cardiol. 2013;61:2194-6.

32. Dieleman JM, van Paassen J, van Dijk D, Arbous MS, Kalkman CJ, Vandenbroucke JP, et al. Prophylactic corticosteroids for cardiopulmonary bypass in adults. Cochrane Database Syst rev. Chichester, UK: John Wiley \& Sons, Ltd; 2011.

33. Weis F, Beiras-Fernandez A, Schelling G, Briegel J, Lang P, Hauer D, et al. Stress doses of hydrocortisone in high-risk patients undergoing cardiac surgery: effects on interleukin-6 to interleukin-10 ratio and early outcome. Crit Care Med. 2009;37:1685-90.

34. Halonen J, Halonen $\mathrm{P}$, Järvinen $\mathrm{O}$, Taskinen $\mathrm{P}$, Auvinen $\mathrm{T}$, Tarkka $\mathrm{M}$, et al. Corticosteroids for the prevention of atrial fibrillation after cardiac surgery: a randomized controlled trial. J Am Med Assoc. 2007;297:1562-7.

35. Rodrigo R, Korantzopoulos P, Cereceda M, Asenjo R, Zamorano J, Villalabeitia $E$, et al. A randomized controlled trial to prevent post-operative atrial fibrillation by antioxidant reinforcement. J Am Coll Cardiol. 2013;62:1457-65.

36. Harling L, Rasoli S, Vecht JA, Ashrafian H, Kourliouros A, Athanasiou T. Do antioxidant vitamins have an anti-arrhythmic effect following cardiac surgery? a meta-analysis of randomised controlled trials. Heart. 2011;15;97(20):1636-42.

37. Scheen AJ. Clinical pharmacokinetics of metformin. Clin Pharmacokinet. 1996;1;30(5):359-71.

38. Cameron AR, Morrison VL, Levin D, Mohan M, Forteath C, Beall C, et al. Anti-inflammatory effects of metformin irrespective of diabetes status. Circ Res. 2016;119:652-65.

39. Williams LK, Padhukasahasram B, Ahmedani BK, Peterson EL, Wells KE, González Burchard E, et al. Differing effects of metformin on glycemic control by race-ethnicity. J Clin Endocrinol Metab. 2014;99:3160-8.

40. Knowler WC, Barrett-Connor E, Fowler SE, Hamman RF, Lachin JM, Walker EA Reduction in the incidence of type 2 diabetes with lifestyle intervention or metformin. N Engl J Med. 2002;346:393-403.

\section{Submit your next manuscript to BioMed Central and we will help you at every step:}

- We accept pre-submission inquiries

- Our selector tool helps you to find the most relevant journal

- We provide round the clock customer support

- Convenient online submission

- Thorough peer review

- Inclusion in PubMed and all major indexing services

- Maximum visibility for your research

Submit your manuscript at www.biomedcentral.com/submit 